\title{
The Absolute Spectator
}

\author{
Alberto Carroggio De Molina \\ University of Barcelona, Faculty of Fine Arts \\ Department of Arts and Conservation-Restoration
}

\begin{abstract}
The painter, as an absolute spectator, reaches the limit of the observable. When analyzing the process of pictorial representation, he realizes that he is observing his own product, because when he decomposes the surface into its components, he discovers the color and beyond color there is nothing. It is necessary to reverse the process of analysis and to undertake the synthesis process: that is, to generate concepts that support actions that, ultimately, are based on personal attitudes, among which confidence in oneself is the culmination of the process and, nevertheless, determines the action from the beginning. From this perspective, the definition of representation is a whole in which the notions used by the mind intervene to elaborate the image of the environment and, consequently, the components of the definition of representation are of a subjective nature.
\end{abstract}

Keywords: Perception, Color, Drawing, Painting, Relativity, Spectator. Representation

\section{INTRODUCTION}

In 1987, I presented my PhD thesis, "Estética en la pintura: el hecho de pintar"1 (Aesthetics in Painting: The Fact of Painting), where I explored the consequences of considering colour as a sensation.

I like to ponder this question, and have asked several scientists about it, some of whom politely dodged the question. I get the feeling that the same happens in science as in painting: thinking is a very risky thing to do.

In this introduction I will review the themes I addressed in previous articles, with some variations. I would like to save readers the tiresome job of having to go from one article to another looking up references.

To think of colour as a sensation forces us to accept all the consequences of the meaning of "sensation". A sensation is, first and foremost, a state of consciousness, and is thus something absolutely individual; a sensation can only be perceived by the subject, and cannot be compared with another subject's sensation; only the person perceiving it is aware of it, and he or she is the only one who can know it. A sensation takes place inside our being, and cannot escape it. This interiority is substantial and embarrassingly possible to accept.

Let us look at a brief medical description of our organ of sight:

"When light enters the eye, it stimulates our photoreceptor cells. Cones and rods are the first-order neurons in our visual pathways. This information then travels to the bipolar cells of the inner nuclear layer of the retina. These are the second-order neurons. Prolongations of these neurons extend into both plexiform layers to make

1 Carroggio, A. (1987), Estética en la pintura: el hecho de pintar, Universitat de Barcelona, http://hdl.handle.net/2445/36692 
connections (...). A layer of ganglion cells creates the layer of the retina's nervous fibres. These fibres converge towards the optic nerve, forming the optic papilla, then perforate the choroid and run through the posterior scleral foramen, interweaving with the lamina cribrosa. The axons continue as the optic nerve, optic chiasm, the optic tract, to end in the lateral geniculate nucleus. The nerve cells of these nuclei form the beginning of the fibres of the geniculocalcarine tract (the optic radiation) which ends in the striate cortex, or visual receptive area along the calcarine fissure in the occipital lobe of the brain."2

A fine description; but what is of interest to us here is that the energy that comes into the eye, after a long and complicated path, reaches the brain, where colour is formed. As there is no return route from the brain to the outside, everything we see, being made up entirely of colour, remains inside the brain, in our minds. The things that we see are the same things we smell, touch, hear, taste, measure, form ideas of, and so on; everything exists inside a single field inside the mind, and this field covers my entire environment, the whole Universe. This means that the Universe, which we take to exist outside ourselves, is made up of the notions the mind forms, and therefore cannot exist previously to our own consciousness.

My consciousness, which only I perceive, distinguishes two forms of knowledge: sensations and concepts. We might then say that the mind works with these two notions to generate the complexity of thought. An idea -a concept- is a sum of concepts and sensations that existed previously. A table is made up of multiple concepts, but we can generally say that it is a surface with a specific colour and dimensions. If the notions of a surface, dimension and colour did not exist previously to the idea of a table, then that idea could not exist. In order for the table to be of a particular colour, the colour must exist before the table. If this were not so, we would be able to imagine having a green table without the colour green existing. In other words, the mind creates new concepts out of previously existing notions -sensations and concepts. In the end, this is what painters do when representing their surroundings: they create a threedimensional image by distributing colours in a certain order. Without colours, there is no image, and without order there is no three-dimensionality.

A definition, then, is a description of all the notions that make up the whole and, clearly, these parts must exist before the whole. If we analyse these concepts in greater depth, we come to a point where we can no longer define something because it will not be formed by previous notions; at this point, we turn to sensation.

Colour as an abstract concept does have a definition; but a colour as a sensation is indefinable. It is not possible to define the colour yellow, or any other colour, because visually, there is nothing previous to the colour as it is experienced by consciousness. A sensation is an act of consciousness, and can only be known by experience.

The essential difference between sensations and concepts is therefore that concepts can be defined.

Now let us use the painter's experience to speculate a little. There is an important qualitative step in the process of forming concepts, which is the point at which the sensation becomes a simple concept. To give an example: a surface would be a simple concept, as it is a "sum" of sensations.- Complex concepts, on the other hand, would be the result of a "sum" of concepts. I

2 Groom, E., (1972), Sensaciones visuales, Universidad Central de Venezuela, p. 54 
think the fact we can create -or perhaps I should say integrate- such sums depends on an innate faculty. Sensations provide no more information than they themselves contain, meaning we need the help of a mental mechanism that will integrate sensations into more complex products, so that visual information -strokes of colour, for example- may be organised into visual surfaces.

Velázquez's Court Dwarf Don Antonio el Inglés is a good example of this phenomenon. If you look at Don Antonio's doublet, you will see it is made up of perfectly differentiated strokes of colour.

This is a display of intelligence. The surface holds an enormous amount of information, and yet in spite of the complexity of the work the information can be perfectly identified. You can appreciate the surface of the coat, its colour, shape and shine; but you can also see the strokes of colour that constitute it. We as viewers can choose to see one thing or the other.

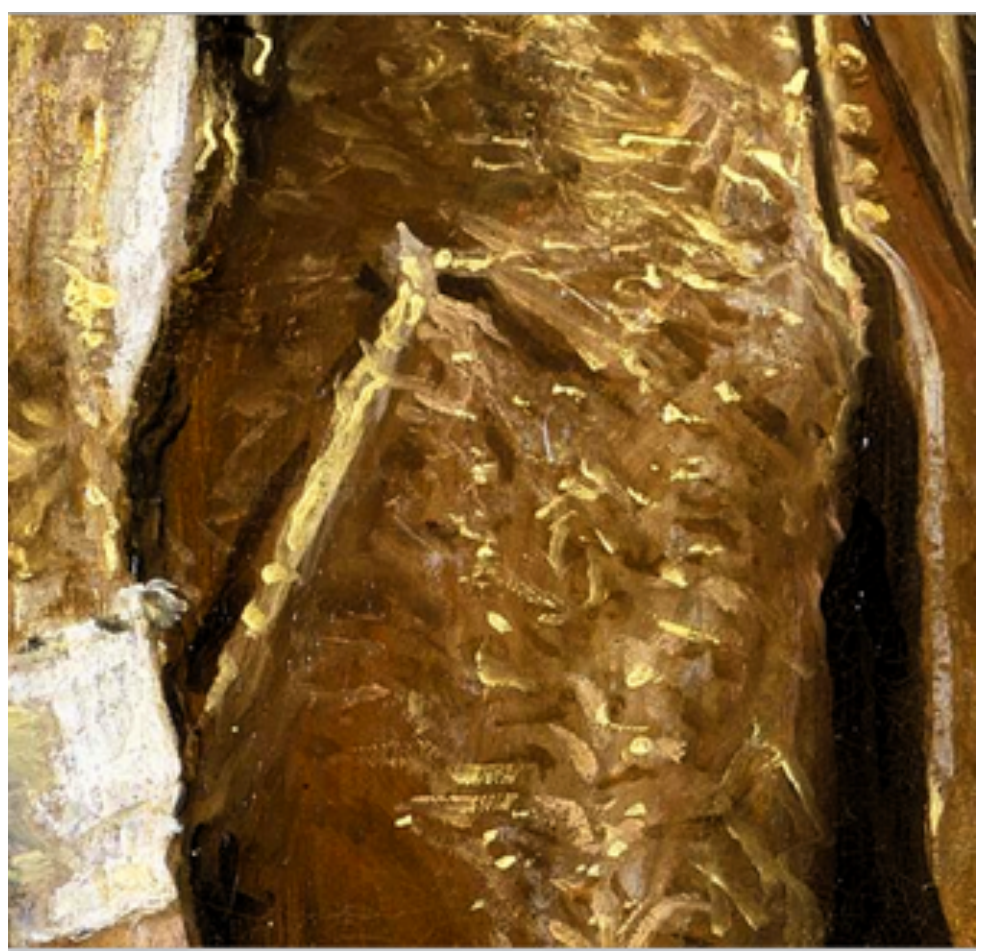

Fig. 1. Detail from Diego Velázquez, Don Antonio el Inglés, 142 x $107 \mathrm{~cm}$, Museo del Prado, Madrid

This was Velázquez`s great discovery: to create surfaces out of patches of colour; because this is what the eye does. This is a very different procedure to chiaroscuro, which "paints" lights and shadows, and in doing so ignores what is on the canvas, that is, stains of colour. The only thing the paintbrush can do is to distribute colours, since that is all there is on the palette. Light and shadow arise from the correct distribution of colours, and so they are concepts, and therefore cannot be applied with a paintbrush.

From this situation, we can deduce that energy reaches our receptors in an ordered state. The Universe groups matter, or at least the matter we perceive, in an ordered fashion, and this order is used by our sight to generate images; if information were not ordered, the brain would be unable to elaborate a response, not having a canon to follow. 
To define a simple concept, then, we need an integrating mechanism, as this depends on two previously existing factors: sensation, and the faculty of integrating. We may then define the surface as the integral of discrete, ordered sensations.

Admittedly, I have invented here a mental mechanism with the capacity to integrate, but some kind of mechanism, whether this or something similar, must exist in order for us as painters to do what we do, which is to use it to make three-dimensional visual elements on a twodimensional surface. We use the mechanism both ways - we can disintegrate the surface into colours, but also bring it together again.

The function of our organ of sight is to elaborate surfaces. To do this, it adjusts its response to optimize the result. Our organ of sight may perceive the same stimulus as different colours; it behaves relatively. One particular pigment may be seen as a number of different colours depending on its surrounding field. The squares in the middle of Fig. 2 were made with the same RGB colour selection, and yet are differently coloured, and their colour would change again on another different background

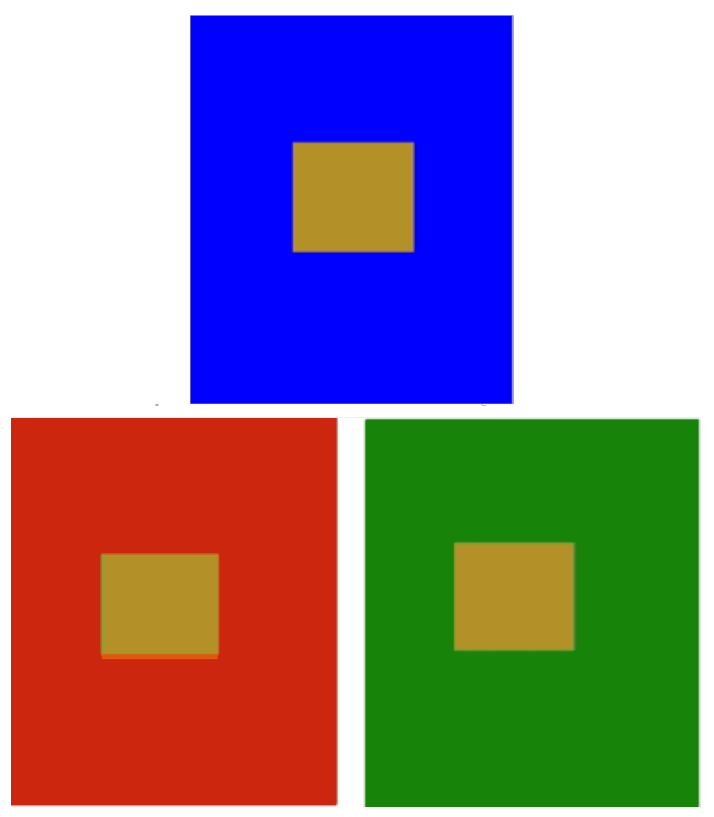

Fig. 2

The painter ends up ignoring the colour of the mixture of pigments he or she sees on the palette and takes note only of what is on the canvas, which is what is of interest. The painter knows that what is on the palette is different to what is seen on the painting, although the mixture of pigments is the same.

Which is the "real" colour here? Which of the colours in the middle in this illustration is the colour we "ought to" see? It would be senseless to think that there is a "perfect" background which would show the colour correctly.

This confirms the idea which introduces this text, of the notion of sensation. Colour is not the pigment, or the amount or quality of energy. Colour is the response of the organ of sight; it is a product the mind elaborates using energy from outside. It is, then, what we see. Our response depends on the visual field as well as the particular conditions of the visual phenomenon, in which even our emotional state could be considered influential. 
We can, of course, measure the intensity, frequency or temperature of light; we can analyse the composition of our pigments; and yet our response - a particular colour - can only be known by the subject who perceives it.

Let us go back to the notion of sensation as an act of consciousness. Following the same criteria, we can add one other sense -time- to the familiar senses of sight, sound, smell, taste and touch that we already know. The sense of time cannot be defined, because in order for this to be possible, we would need to use notions previous to the idea of time, which would be decidedly contradictory. Time behaves as a sensation, and its passing is subject to perception. It goes faster or slower depending on the state of mind of the subject experiencing it.

Here, we must qualify those equations in which time is used within a mathematical expression. Introducing time into an equation is like attributing a mathematical value to colour. Time as a sensation behaves much like colour does.

Let us not forget that what we are looking at here is the inside of the mind, and that everything we know has been formed inside it. When we speak of time, what kind of time are we talking about - the time that takes shape inside the mind, or what we suppose to be the time of the Universe? If we mean the latter, what receptor do we have for perceiving it? And why would the Universe create a time it has no use for?

It is hard to believe that a Universe made of matter organised into infinite spheres that clash and destroy each other would have any kind of urgent need to create time. It is also hard to believe that the same Universe, which took thousands of millions of years to create something as complex as life -which it can extinguish with utter indifference - would have complex capacities in its initial stages, and could have devised relative behaviour. Relativity does not pertain to the Universe; it pertains to the spectator, and involves the way some of our organs behave as they generate the sensory responses we use to construct our idea of the Universe.

It is not my business here to draw scientific conclusions that may be derived from accepting time as a sensation; but I have the impression that our position as spectators is a confusing one. We must make clear when it is that we are perceiving information from an external Universe, and when what we are perceiving is actually a result of something constructed by our own minds.

\section{THE LIMIT OF THE SPECTATOR}

We are, I am, the absolute spectator; there is no other. The figurative painter confronts the product of his or her own mind. We make three-dimensional objects, on a two-dimensional surface, by creating surfaces and distributing them in the three-dimensional space we have created. To create three-dimensional surfaces, we must, of course, have previously visually "destroyed" the two-dimensional surface. We destroy the surface we work on, and create the space into which we engender the three-dimensional object we want to represent. I am not playing with words here; this is real: the painter sees his or her desired representational object on the unpainted canvas without having made a single stroke, and creates a vision of a surface out of any item of visual information.

At a certain point when we analyse the process of painterly representation, we come to the limit of the observable: the observer turns back on him/herself and realises that he or she is observing a product of his/her own mind. The action is not taking place on an outside body, but on products made by the mind itself. The surface of painted objects is a consequence of having correctly distributed certain colours, but if colour is a product of the mind, then so is the 
surface. On the canvas, there is only one surface, which can be, however, attributed to the object it represents - any object, and any part of that object; but it can also be the surface of the canvas, or the paint itself. The surface is universal; all that changes is what we ascribe to it.

We cannot go on from there, because if we decompose the surface into its components, we end up with colour, and there is nothing beyond colour. We must then reverse the analytical process and begin to synthesise.

How do we define the act of representing with these ingredients? We might say that representing is the ordered distribution of colours on a surface with the aim of copying the image of our visual surroundings. Very well, but how is this to be done?

To do this requires that we conceptualise; that we carry out acts based on concepts which, ultimately, are grounded in personal attitudes, among which self-confidence is the culmination of the process, and yet also determines our acts from the very beginning. From this perspective, the definition of "representation" is a whole, in which all the notions the mind has used to elaborate its image of its surroundings come into play. The components of our definition of representation are therefore of a subjective nature.

For the painter, there is no privileged spectator able to define the phenomenon -any phenomenon- from an optimal point of view; the painter him/herself is the absolute spectator, and defines what it is he or she perceives of the phenomenon, not the phenomenon itself; because the phenomenon as such is limitless. What we are considering here is thus an absolutely subjective point of view in which the painter, as a spectator, elaborates the notions of what he or she represents, and sets in place the concepts that define his or her acts. I understand Sorolla saying that he was afraid, because our definition of the act of representing is grounded on decisions based on personal reality. The order of action, even if it is grounded in similar forms of knowledge, can derive towards attitudes that define the visual environment in different ways, and therefore create different results. Deciding that the image we are representing is on the surface of the canvas or inside it, in the depth of the painterly space; that it is a set of discrete colours, or a surface made up of volumes, will create substantially different results, and yet I cannot be sure which of these results will be the most correct, because I cannot enter the mind of other painters. I can know which outcome gives me more pleasure, or is the easiest to achieve, but I cannot reject one in favour of another. I cannot even be sure that in the end they will inadvertently fuse into a single form, and that my act will ultimately be a single, unique act.

I might think that the different forms or styles of certain painters could have been stages leading up to this final phase. Perhaps these stages -and I think here of the painter Joaquim $\mathrm{Mir}^{3}$ - being as they are the path leading to the final phase, are correct; they may even be abstractions of certain aspects of the painter's total concept of representation. Mir is the explosion of a way of doing; the pleasure of adjusting colour, to the point where the theme is ignored at the expense of his sole interest in colour. His figures are true landscapes filled with colour, which he fits onto the frame of his rather careless drawing. He moves away from the notion of total representation, but adheres so closely to the idea of adjusting colour that action in his case becomes mysticism, pure action. According to stories from his workshops, his preparations for his work included a very earthy kind of ritual which he considered absolutely necessary.

3 Mir i Trinxet, J. (1873 - 1940) 
But the concept is grounded in the will, and our will is grounded in pleasure. There is no observer outside the act, or outside the event, because we are the makers of the event, and all of our faculties intervene in it.

Sorolla's fear, the painter's fear, is one of the factors that come into the result almost as much as our lack of knowledge of our medium. Fear prevents us from judging the outcome of and assessing our work. Fear binds the painter and stops him or her from seeing the reality of what is being painted.

On the other hand, method may be the refuge of insecurity, and should be overcome, because method may be obligation, the desire to do things well, and because of this, it can lead you to ignore capabilities and attitudes that come into the making of the work.

Action, I think, can acquire schizoid hues when its natural sense is reversed. Sometimes, a painter seems to be studying him or herself in order to find out how to act, without understanding that his or her attention should be directed outwardly, towards the model.

If I seem to be refusing method here, this is not so: action should be grounded in knowledge. Method must become knowledge, not obligation. The order of action cannot be imposed; it must be accepted, as it comes from the self, it is the self, not something outside it.

Our aim is the freedom that comes from solitude, from purity of action, from play and the pleasure of playing.

\section{CONCLUSIONS}

It is hard to reach any conclusions on the position of the absolute spectator: he or she is everything, has created everything, and so his or her self extends into the entire Universe. He, she, is the Universe.

Does the study of the Universe define the characteristics of the Universe outside us, or does it simply provide an explanation of the mental faculties of the observer? If we think of time, what "time" are we speaking of? We can say nothing of time as a sensation, just as we can say nothing of the colour yellow or the colour red, of the smell of garlic, or of the tactile sensation.

Our faculties are an exponent of the Universe's behaviour. Ultimately, we are an evolved form of the Universe. Since we are the Universe studying the Universe, then the results of science must be true. But the position of the spectator has always been a concern to me. What lucky spectator is able to say that the Earth revolves around the Sun? Who can say his or her position is the "right" one? Physics creates equations that define phenomena for a spectator situated at any point in the Universe - but does such a point exist?

Professor Corcoran's ${ }^{4}$ lockers preoccupy me. This, in the end, is what we are. Is there any way of ascertaining that they are only lockers? I am the absolute spectator, but what do I observe?

Ultimately, I have to accept that I live according to information generated by my own mind. Any act must be resolved from the mind, and representation as such is nothing but a display of human faculties.

${ }^{4}$ Lem, S,. (1985), Diarios de las estrellas. Viajes y memorias, Barcelona, Ed. Bruguera, p.164 


\section{References}

We must recognize that there is no methodological literature on representation in painting. It is true that we find many publications that expose extensive knowledge about painting, but, in general, belong to the world of history, to speculation or are manuals for the application of different procedures. The figurative painter must begin a personal journey. His knowledge comes directly from his activity and does not have the support of an extensive and proven documentation, as happens in other branches of knowledge. Diversity is the characteristic of his collection of reference books.

I feel indebted to very different authors, because as researchers of a single spectacle, they express ideas that are reflected in my activity as a painter. Concepts such as relativity (Einstein 1874 - 1955) or the notion of continuity (Louis de Broglie 1892 - 1987) have their application in both painting and drawing of the natural.

If they are sometimes included, in the short bibliography of the articles I publish, it is because of a feeling of gratitude for the knowledge they have transmitted to me and from which I have benefited.

Carroggio, A. Estética en la pintura: el hecho de pintar, Universitat de Barcelona, http://hdl.handle.net/2445/36692 (1987)

Einstein, A. Adolf Grünbaum, A. S. Eddington y Otros, La Teoría de la Relatividad, Alianza Editorial, Madrid, (1973)

Einstein, A. Sobre la teoría de la relatividad especial y general, Alianza Editorial. Madrid, (1984)

Groom, E. Sensaciones visuales, Universidad Central de Venezuela, (1972)

Heisenberg, W. Encuentros y Conversaciones con Einstein y Otros Ensayos, Alianza Editorial S.A., Madrid, (1979)

Lem, S. Diarios de las Estrellas. Viajes y Memorias, Barcelona, Ed. Bruguera, (1985) 